\title{
ULTRAJANTES, INEVITÁVEIS? DEBATENDO ANALOGIAS HISTÓRICAS NA COBERTURA DO CONFLITO ISRAELO-PALESTINO ${ }^{i}$
}

\author{
Jérôme Bourdon ${ }^{\mathrm{ii}}$
}

Resumo: Este artigo explora o debate que envolveu o uso de analogias na cobertura do conflito israelo-palestino, analisando, em profundidade, dois "casos de analogias" baseados no corpus pesquisado no Lexis-Nexis: o caso de Auschwitz-Saramago, 2002, (55 artigos), e o caso de Apartheid-Carter, 2006-2010, (144 artigos). Usando a tripartição clássica Aristotélica de logos, ethos e pathos, o artigo se desdobra sobre a estrutura argumentativa de controvérsias. Carter e Saramago usaram a combinação do próprio status e a essência controversa de suas analogias para estimular um debate. Os comentaristas centraram muito mais no ethos (argumentos em torno da autoridade e do caráter dos autores) e no pathos e tenderam a ignorar o logos (a verdadeira importância da analogia). Opositores, que constituíam a maior parte dos comentaristas, consideravam as analogias um meio de transmitir e mobilizar julgamento contra um dos envolvidos no conflito (no nosso caso, Israel). Esta análise sugere que, apesar do apelo para um uso mais cauteloso das analogias discutidas (ou mesmo sua proibição), os participantes no debate sobre os conflitos israelo-palestinos são obrigados a recorrer a elas, ainda que apenas para condená-las.

Palavras-chave: Controvérsia Pública. Analogia Histórica. Carter. Saramago. Shoah.

\begin{abstract}
This article explores the debate that has surrounded the use of analogies in coverage of the Israeli-Palestinian conflict, analyzing in depth two "analogy affairs" on the basis of a LexisNexis corpus: the 2002 Auschwitz-Saramago affair (55 items) and the 2006-2010 ApartheidCarter affair (144 items). Using the classic Aristotelian tripartition of logos, ethos and pathos, the article unfolds the argumentative structure of the controversies. Carter and Saramago used the combination of their own personal status and the controversial nature of their analogies to trigger a debate. Commentators focused very much on the ethos (arguments around the authority and the character of the authors) and the pathos, and tended to ignore the logos (the factual relevance of the analogy). Opponents, who made up the majority of commentators, considered analogies as a way of passing judgment on and mobilizing against one of the actors in the conflict (Israel, in our cases). This analysis suggests that, despite the call for a more cautious use of (or even a prohibition of) the analogies discussed, participants in the debate on the Israeli-Palestinian conflicts are bound to resort to them - even if only to condemn them.
\end{abstract}

Keywords: Public Controversy. Historical Analogy. Carter. Saramago. Shoah.

i Referência da publicação original:

BOURDON, Jérôme. Outrageous, inescapable? Debating historical analogies in the coverage of the Israeli-Palestinian conflict. SAGE publication Discourse \& Communication. August 2015 9:407-422, first published on April 21, 2015.

ii Gostaria de agradecer a Michal Aviad, a Daniele Torck e a Eithan Orkibi pelos comentários e sugestões na primeira versão deste artigo. 
EID\&A - Revista Eletrônica de Estudos Integrados em Discurso e Argumentação, Ilhéus, n. esp. ADARR, mai.2016.

\section{Introdução}

Enfatizando as grandes analogias históricas em um contexto político altamente sensível (o conflito israelo-palestino), este estudo baseia-se em um crescente número de pesquisas sobre o papel das comparações, analogias e metáforas nos telejornais (cf. KENNEDY, 2000; KITIS e MILAPIDES, 1997; LULE, 2004; SONTAG, 1990; HOUCHIN-WINFIELD et al., 2002). Entretanto, contrariamente a essas pesquisas, tanto quanto à maioria das pesquisas que cobrem esse conflito específico, não proponho uma avaliação crítica do uso de figuras de linguagem. Em vez disso, analiso a estrutura argumentativa de debates sobre analogias notoriamente usadas em referência a Israel-Palestina. Esses debates são estimulados por autores que as utilizam em determinado contexto, suscitando reações de comentaristas.

Eu usei a palavra "autores", porque é assim que os instigadores são tratados no debate, mas é preciso deixar claro que as analogias usadas têm uma longa história, como veremos, e um não rastreável autor original. Pelo contrário, elas são periodicamente retomadas e a intensidade da reação depende muito do status do autor.

Começo definindo o que entendo por analogia para, em seguida, focalizar dois debates bastante ricos que nos permitem discorrer sobre muitos argumentos cuja utilização é frequente. Eu analiso os argumentos pró e contra as analogias, mostrando como eles não podem conduzir ao entendimento mútuo, já que são usados em contextos em que ambos os lados estão, a princípio, desinteressados de compreender o outro, que é sempre condenado. Na verdade, o que justifica o uso da analogia por um dos lados é precisamente que esse uso aliena o outro. Se justificadas, encorajadas ou proibidas, as analogias têm o poder de suscitar um debate público, um poder que é parcialmente explicado pela estrutura dos debates.

\section{1. Últimos avanços e definições}

Pesquisadores do discurso jornalístico, tais como Lule (2004) e Sontag (1990), têm dedicado mais atenção a metáforas do que a analogias. No entanto, existem algumas semelhanças entre as duas. Espera-se que $\mathrm{O}$ discurso jornalístico constitua-se, principalmente, de afirmações factuais e não de "metaforização artificial nos itens jornalísticos comuns" (VAN DIJK, 1988, p. 84), e nem de analogias surpreendentes. 
EID\&A - Revista Eletrônica de Estudos Integrados em Discurso e Argumentação, Ilhéus, n. esp. ADARR, mai.2016.

As metáforas no discurso jornalístico tendem a ser naturalizadas, o que ajuda a explicar por que autores tendiam a desprestigiá-las nas notícias, especialmente postas em contextos que permitiam que alguma ideologia fosse sub-repticiamente transmitida aos leitores, como um discurso próguerra (como em LAKOFF, 2003 e em LULE, 2004).

Nossos autores e comentaristas usam o termo "analogia" e, em menor grau, "comparação" ou "paralelo", mas todos se referem a enunciados (escritos ou orais) em que o conflito israelo-palestino é discutido, relatado ou apresentado em conexão a outra situação histórica do passado: o regime do Apartheid (1948-1967) ou a política nazista contra os judeus.

Seguindo Perelman e Olbrechts-Tyteca (1969), denomino a situação principal (o conflito israelo-palestino) tema, e a situação auxiliar (Apartheid ou política nazista), foro da analogia. Numa analogia, ao contrário da metáfora, tema e foro estão ambos presentes. Uma analogia difere da comparação, uma vez que toma a forma de justaposição de termos relacionados ao tema e ao foro, não traz a palavra "como", é breve - pelo menos quando é empregada por nossos autores - e não inclui uma consideração sistemática termo-a-termo dos componentes do tema e do foro. Nesse sentido, a analogia é o meio termo entre a comparação desenvolvida, mais explícita, e a mais aberta, metáfora implícita.

Apesar (ou por causa) do considerável trabalho' sobre essas noções, não há um acordo claro sobre as diferenças entre a comparação, a analogia e a metáfora, que também é chamada de "uma breve comparação" (RICOEUR, 1975, p. 153).

As analogias são semanticamente instáveis, especialmente entre temas complexos e foros como os discutidos aqui. É fácil explorar o par principal, A$B$, bem como extrair subanalogias. Além disso, uma analogia pode facilmente ser desenvolvida (PERELMAN; OLBRECHTS-TYTECA, 1969, p. 386) através do tempo e do espaço, como por exemplo:

- A é como B (Israel-Palestina é como Apartheid);

- C é como D (Palestinos são como negros);

- e/ou E é como F (o passado: boicote da África do Sul é como o futuro: boicote de Israel);

1 Ver notavelmente Ricoeur (1975) para uma perspectiva filosófica integrada sobre metáfora. 
EID\&A - Revista Eletrônica de Estudos Integrados em Discurso e Argumentação, Ilhéus, n. esp. ADARR, mai.2016.

- e/ou G é como H (o passado: fim do Apartheid, a igualdade formal entre brancos e negros é como o futuro: fim da ocupação de Israel, igualdade formal entre judeus e árabes) etc.

Essa instabilidade pode afetar a mensagem pretendida pelo autor: ele (há um "ele" em ambos os estudos de caso) não pode controlar o debate, uma vez que o efeito analógico já está concretizado (voltaremos a isso mais tarde).

Diferente das metáforas nos estudos das notícias mencionadas, essas analogias não foram inicialmente proferidas por jornalistas, mas sim por personalidades não midiáticas com um alto nível de notoriedade. Como veremos, essas personalidades tinham a mídia em mente quando evocaram as analogias.

As analogias estudadas dividem outra característica: elas são históricas, um tipo que tem sido muito usado em argumentações políticas (NEUSTADT; MAY, 1986, cap. 3). Na pesquisa midiática, Houchin-Winfield et al. (2002) mostraram como analogias históricas foram usadas nas coberturas jornalísticas britânicas e americanas quanto ao 11 de setembro de 2011. Kennedy (2000, p. 255), embora use a palavra "metáfora", considerou também as analogias históricas específicas mobilizadas na guerra de Kosovo, tal como a "OTAN é Nazista".

A cobertura do tema, o conflito israelo-palestino, tem sido calorosamente debatida por muitos anos e foi renovada durante a Segunda Intifada (2000-2005), (BOURDON, 2009). Autores que estudam essa cobertura tendem a tomar partido e criticá-la, ou como pró-Israel, principalmente nos EUA (cf. ZELIZER et al., 2002), ou como pró-Palestina, principalmente na Europa (cf. FLEURY; WALTER, 2008). Além disso, a crítica radical a Israel pela e/ou por meio da mídia foi rapidamente associada a uma nova forma de antissemitismo (cf. POLIAKOV, 1983). Taguieff (2004) tem reavivado com sucesso a expressão "novo antissemitismo", usada pela primeira vez na década de 1970. Ele inclui no "novo antissemitismo" a condenação de Israel como "Estado racista", especialmente por meio de analogias com o Terceiro Reich ou com o regime do Apartheid (TAGUIEFF, 2009). Ao descrever Israel como Estado racista e ao empregar a analogia nazista, foram incluídos exemplos numa definição controversa de antissemitismo adotada em 2005 
EID\&A - Revista Eletrônica de Estudos Integrados em Discurso e Argumentação, Ilhéus, n. esp. ADARR, mai.2016.

pelo Observatório Europeu do Racismo e da Xenofobia (EUMC), abandonada em 2009, mas retomada posteriormente por uma organização menos oficial ${ }^{2}$.

No mundo acadêmico, os analistas do discurso também condenaram essa analogia. Koren considera a analogia Holocausto, especialmente quando usada contra Israel, um exemplo de discurso que "mais ou menos explicitamente objetiva a destruição física ou simbólica do alvo" (KOREN, 2012) e que deve ser condenada como tal. Meu posicionamento aqui é diferente, pois é um pouco difícil traçar a fronteira entre o uso condenável e o legítimo de uma analogia.

\section{Metodologia: Seleção da analogia}

Procedi a uma investigação no Lexis-Nexis "English News", em todas as datas (de 1977 a 2014), usando a seguinte busca: (analogy OR compar! OR parallel) AND (Israel OR Palest!) AND ( $X$ ), em que $X$ era uma das analogias históricas que eu havia encontrado no decorrer de uma extensa pesquisa sobre a cobertura do conflito (BOURDON, 2009). Depois de checar uma amostra, restringi a pesquisa para aproximadamente 50 palavras (aproximadamente um parágrafo curto) entre a analogia e "Israel" ou "Palestina", a fim de excluir os artigos longos que lidavam com analogias não relacionadas ao conflito. Além disso, adicionei Auschwitz como a principal metonímia a Holocausto. Os resultados estão resumidos na tabela a seguir:

\section{TABELA 1 - Analogia histórica na cobertura de Israel-Palestina. Lexis-Nexis} 1977-2014

\begin{tabular}{|c|c|c|}
\hline Posição & Analogia & Número de palavras \\
\hline 1 & Holocausto/Auschwitz & 312 \\
\hline 2 & Apartheid & 222 \\
\hline 3 & Northern Ireland & 51 \\
\hline 4 & Indígenas/Americanos Nativos & 37 \\
\hline 5 & Movimentos de Direitos Civis & 19 \\
\hline
\end{tabular}

As analogias Holocausto/Auschwitz e Apartheid foram notórias, como ficou confirmado por meio de pesquisas em dois grandes websites, um pró- 
EID\&A - Revista Eletrônica de Estudos Integrados em Discurso e Argumentação, Ilhéus, n. esp. ADARR, mai.2016.

Palestina (The Electronic Intifada - arquivada em 2000) e outro pró-Israel (Camera - Committee for Accuracy in Middle East Reporting in America, arquivada em 1992). Ambos dedicaram grandes esforços para refutação ou justificação de analogias, com especial atenção às do Holocausto e do Apartheid.

Em seguida, adicionei uma segunda restrição, enfatizando dois dos maiores "casos de analogias" do meu corpus. Essas analogias desencadearam o maior número de reações e tiveram uma cauda longa $a^{3}$, o que significa que elas foram citadas muito tempo depois de seu uso original. Dessa forma, elas ofereceram a melhor oportunidade para cobrir uma grande variedade (se não um vasto leque) de argumentos.

Começo analisando o caso Auschwitz-Saramago (2002), que foi desencadeado pelo seguinte evento: "Português ganhador do prêmio Nobel José Saramago [...] comparou a ocupação israelense dos territórios palestinos ao campo de extermínio nazista de Auschwitz, durante uma visita de notáveis escritores à cidade de Ramallah, na Cisjordânia" (AFP, 25.03.2002) ${ }^{4}$. A visita havia gerado uma grande e pré-planejada cobertura da mídia, devido à reputação dos escritores visitantes: o espanhol Juan Goytisolo, o sul africano Breyten Breytenbach, o americano Russell Banks e o francês Christian Salmon. Foi um festival de analogias relacionadas à cultura nacional de cada escritor: Russell Banks referia ao tratamento dos Americanos Nativos, Salomon ao colonialismo francês, Breytenbach ao Apartheid. Enquanto outros foram mencionados no meu corpus, Saramago roubou a cena com "Ramallah é como Auschwitz".

O segundo caso de que irei tratar, começou em novembro de 2006, com a publicação do livro do ex-presidente dos EUA, Jimmy Carter, intitulado Palestine Peace Not Apartheid ${ }^{5}$, do qual não discutirei o conteúdo. Muitos resenhistas notaram que a palavra apartheid quase não foi mencionada; no entanto: "[...] a maior parte da indignação surgiu por causa do uso da palavra apartheid no título, aparentemente igualando o drama dos palestinos de hoje

3 N.T.: Cauda longa, tradução do original long tail, termo utilizado na Estatística para identificar distribuições de dados, como a curva de Pareto. Quando comparada a uma distribuição normal, ou Gaussiana, a cauda longa apresenta uma quantidade muito maior de dados ao longo da cauda.

4 Todas as referências com data exata remetem aos corpora utilizados para a análise do discurso e figuram numa lista distinta das referências bibliográficas acadêmicas, que estão indicadas apenas pelo ano.

5 N.T.: Na tradução portuguesa, a obra recebeu o título: Palestina. Paz, sim. Apartheid, não. Lisboa: QuidNovi, 2007. 
EID\&A - Revista Eletrônica de Estudos Integrados em Discurso e Argumentação, Ilhéus, n. esp. ADARR, mai.2016.

ao das vítimas da segregação racial do governo da África do Sul" (BOSMAN, 14.12.2006).

Ambos os debates ilustram a alta instabilidade semântica de "grandes" analogias. O emprego de apartheid, por Carter, no título, com a incomum concatenação de palavras (muitos comentaristas o reescreveram com dois pontos: Palestine: Peace Not Apartheid), permitiu muitas interpretações.

Os críticos de Carter, em particular, interpretaram o título como uma afirmação de que a política de Israel face aos árabes era como o Apartheid em relação às bases jurídicas racistas do regime sul-africano, e alguns sugeriram que ele tenha condenado não só as políticas de Israel em relação aos árabes israelenses, mas também a ocupação da Cisjordânia e Gaza.

Quanto a Saramago, ele foi amplamente citado: "O que está acontecendo na Palestina [...] nós podemos comparar ao que aconteceu em Auschwitz (Agence France-Press - AFP, 25.03.2002); ou, no estilo indireto, "falando de Ramallah estar se tornando um campo de concentração" (HASS, 26.03.2002); ou mais adiante: "a comparação de Saramago da Cisjordânia com Auschwitz" (BURUMA, 26.04.2002). Note-se que Buruma usou o verbo "comparar", mas sem desenvolver termo-a-termo a comparação entre tema e foro. Outros comentaristas usaram as palavras "analogia" ou "paralelo".

Como o meu corpus se origina do Lexis-Nexis, na categoria "English News", eu lido, sobretudo, com as mídias britânica e americana, além de jornais israelenses em língua inglesa (principalmente o Haaretz em inglês e o Jerusalem Post).

Há uma clara diferença entre os dois estudos de caso. A maior parte dos artigos sobre a utilização, por Carter, da palavra apartheid se origina nos EUA, e $\mathrm{O}$ assunto era concernente principalmente aos americanos. A imprensa britânica cobriu o episódio Carter-Apartheid sobretudo como um fenômeno dos EUA ligado especificamente à indignação dos americanos (e dos judeusamericanos). Saramago-Auschwitz, por outro lado, foi comentado tanto no Reino Unido quanto nos Estados Unidos. Obviamente, ambos os casos tiveram repercussões internacionais. O livro de Carter foi traduzido, e Saramago é autor internacional. Entretanto, eu decidi não entrar nesse assunto, pois já havia material abundante a seu respeito.

O material reunido abrange uma variedade de gêneros da mídia, incluindo despachos das agências de notícias, reportagens de jornais, entrevistas com ambos os autores, editoriais e transcrições de rádio. $O$ 
EID\&A - Revista Eletrônica de Estudos Integrados em Discurso e Argumentação, Ilhéus, n. esp. ADARR, mai.2016.

material sobre Apartheid-Carter inclui 144 artigos: 22 artigos entre 22 de novembro e 31 de dezembro de 2006, 43 de 2007, e 66 entre 2008 e 2010, momento em que o assunto quase já havia desaparecido. Em seguida, porém, ele voltou a ressurgir com menor intensidade no caso Kerry-Apartheid (13 artigos entre $1^{\circ}$ de janeiro e 25 de maio de 2014 - ver a conclusão).

Para Auschwitz-Saramago, há 55 artigos: 26 entre 25 de março e 31 de dezembro de 2002, 19 entre 31 de dezembro e 9 de maio de 2010, e 10 obituários relembrando o caso de 2002 entre 18 de junho de 2010 e 15 de agosto de 2010, após a morte de Saramago. O caso Apartheid-Carter tem uma cauda mais longa (e ainda não está terminada).

Para analisar os argumentos, utilizarei a divisão aristotélica clássica entre logos, pathos e ethos. Em primeiro lugar, discutirei os argumentos sobre o logos: a coerência lógica do discurso, especificamente a coerência da analogia entre dois eventos/situações. Isso inclui a discussão sobre a (in)adequação histórica da analogia. O argumento lógico é também conhecido como argumentum ad judicium: "o uso de provas retiradas de quaisquer fundamentos de conhecimento ou de probabilidade" (LOCKE apud WATSON, 1992, p. 9).

Considerarei a possibilidade de relevância factual futura (ad futurum judicium) nos casos em que uma analogia tenha sido usada para chamar a atenção. Em seguida, abordarei os argumentos sobre o pathos, a parte da retórica que visa a desencadear emoções nos auditórios: aqui, os debates girarão em torno do uso da analogia como provocação.

Finalmente, abordarei os argumentos sobre o ethos - as características do autor. Isso incluirá argumentos relacionados à autoridade social do autor (argumentum ad verucundiam). Além disso, discutirei o argumento tu quoque (até tu), usado pelo autor e por seus apoiadores em defesa da analogia: a menção de seu uso pelo "outro lado" (diversas vezes definido) na polêmica. O ethos também inclui argumentos ad hominem, que estão relacionados às individualidades do autor.

\section{Logos: a relevância factual da analogia}

Inicio com o que poderia ser o centro dos debates: existe uma semelhança factual entre tema e foro? Aqui, as diferenças foram muito marcantes. Para Carter, a rejeição foi a reação dominante, especialmente na 
EID\&A - Revista Eletrônica de Estudos Integrados em Discurso e Argumentação, Ilhéus, n. esp. ADARR, mai.2016.

mídia dos EUA e, em menor grau, no Reino Unido. Na época em que o livro de Carter foi publicado, já havia paralelismos estabelecidos entre a ocupação de Israel e apartheid (cf. GLASER, 2003) - e o uso da comparação para chamar a atenção existia há muito tempo.

Por sua vez, a analogia Saramago-Auschwitz foi rejeitada quase por unanimidade, na medida em que quase ninguém se preocupou em discuti-la. Aqui está uma rejeição típica da analogia do Holocausto (por um intelectual de esquerda israelense): "É legítimo comparar [...] quaisquer aspectos da presença israelense nos territórios ocupados ao Holocausto? Absolutamente, não! Sob nenhuma circunstância concebível" (HAKIN, 30.11.2004).

Quase nenhum comentarista achou prudente refutar a analogia por meio da identificação de diferenças factuais. Encontrei apenas uma refutação claramente baseada em fatos, numa última referência a Saramago: "Não importa que no momento em que Saramago visitou Ramallah cerca de 1.500 palestinos tenham sido mortos na Intifada, já que, por dia, aproximadamente 2.000 judeus eram assassinados em Auschwitz" (The Australian, 18.12.2006).

Após citar Saramago, a Agence France-Press (AFP - 25.032002) deu informações sobre Auschwitz, sem qualquer comentário sobre Ramallah: "Auschwitz era o mais notório campo de extermínio operado pelo regime nazista da Alemanha durante a Segunda Guerra Mundial, onde milhões de judeus e outros prisioneiros foram mortos". A isso, seguiu-se uma citação de um porta-voz do Ministério das Relações Exteriores israelense: "Sr. Saramago mostra uma completa cegueira e uma amnésia histórica, uma vez que ele está fazendo uma comparação com o incomparável". Aqui, a refutação está implícita. Apresentar dados sobre Auschwitz, seguido de uma caracterização da analogia como uma "comparação com o incomparável", implica uma comparação que não está fundamentada em fatos. No entanto, a maioria dos artigos simplesmente menosprezou Saramago, tendo-o ignorante ${ }^{6}$, e a sua analogia como tão absurda que não houve necessidade de refutá-la.

O único a reivindicar algum tipo de semelhança entre as duas situações foi o próprio Saramago, embora de forma complicada. Ele afirmou à AFP (25.03.2002): "Enquanto guardar na memória todas as distâncias do tempo e lugares, é a mesma coisa". Nove meses depois, ele afirmou ao jornalista britânico: "Veja bem, eu não disse que Ramallah era o mesmo que Auschwitz, isso seria estúpido. O que eu disse era que o espírito de Auschwitz estava

6 Ver adiante, quando trataremos dos argumentos ethoicos. 
EID\&A - Revista Eletrônica de Estudos Integrados em Discurso e Argumentação, Ilhéus, n. esp. ADARR, mai.2016.

presente em Ramallah" (EVANS, 28.12.2002). Outra citação: "O que está acontecendo é mais ou menos o mesmo" (DALRYMPLE, 12.04.2002). Sua referência a possíveis câmaras de gás foi citada seis vezes, incluindo: "Quando um repórter observou que não existem câmaras de gás em Ramallah, como havia nos campos de extermínio nazista, Saramago respondeu: Ainda não existem câmaras de gás. Mas isso não significa que nunca existirão câmaras de gás [...] pode-se matar sem haver câmaras de gás" (AP, 26.03.2002). A falta de precisão é notável e pode ser explicada pelo desejo de provocar.

A rejeição imediata da analogia Carter-Apartheid, como absurda (ou algo pior), também ocorreu, mas muito raramente. $O$ diretor do Carter Center, que se demitiu logo após a publicação do livro, escreveu para o New York Sun dizendo que o título era "muito provocativo até para a gráfica" (citado, entre muitos outros, por AP, 08.12.2006).

Alan Dershowitz (02.12.2006), em um artigo muito citado, rejeitou a analogia de imediato e, consequentemente, o livro todo: “A decisão de Jimmy Carter quanto ao título de sua nova arenga anti-Israel, Palestine: Peace Not Apartheid (dois pontos adicionados), diz tudo. $O$ uso da controversa palavra apartheid pelo ex-presidente, sugerindo uma analogia com as odiosas políticas da África do Sul, é, particularmente, ultrajante [...]".

Outros comentaristas, inclusive alguns que haviam elogiado Carter, refutaram a analogia ao apontar uma única, e para eles óbvia, diferença entre tema e foro: o caráter racista do regime de apartheid, que eles julgaram inaplicável a Israel. Nos EUA, o tom foi de uma completa refutação, até mesmo por apoiadores de Carter: "Eu felicito o presidente [...]; acho, porém, que, neste caso, ele usou um termo equivocado" (NPR, 12.01.2007). Outro menor desacordo também foi observado: "Se isso é Apartheid, então quem é o Mandela palestino?" (Jewish Forward, 19.01.2007). Observe-se que essa específica refutação da analogia, feita por jornal judaico, desloca a culpa dos israelenses para os palestinos.

Alguns comentaristas americanos ofereceram apoio qualificado à analogia, destacando similaridades ao lado das diferenças: "Dito isso, Carter não está errado por ver analogias com aspectos do apartheid" (COHEN, 07.02.2007). O único comentarista americano a fazer uma defesa detalhada da analogia foi, novamente, seu autor: "Essa é uma palavra que porta uma descrição muito precisa da separação forçada, na Cisjordânia, entre israelenses e palestinos, e da ferramenta de dominação e opressão de 
EID\&A - Revista Eletrônica de Estudos Integrados em Discurso e Argumentação, Ilhéus, n. esp. ADARR, mai.2016.

palestinos" (CARTER, NPR, 25.01.2007). Os comentaristas britânicos (alguns jornalistas identificados com a esquerda liberal) estavam, por sua vez, muito mais dispostos a oferecer apoio, frequentemente inadequado, à analogia: "Ninguém que tenha visto palestinos subjugados, lutando com o seu cotidiano ao lado de colonos judeus armados, pode discordar disso" (BLACK, 17.02.2007).

Outro correspondente sênior britânico voltou a refletir a respeito do livro de Carter, alegando ter ele quebrado o "tradicional tabu" existente contra toda e qualquer insinuação de que "Israel opere um sistema de apartheid nos territórios ocupados" (COOK, 27.11.2009), ecoando, assim, um editorial anterior de um professor palestino-americano, que já havia elogiado Carter por "quebrar o tabu de críticas a Israel” (BISHARAT, 02.02.2007).

Embora ele tenha defendido a precisão factual da analogia, o próprio Carter insistiu que isso não era sobre "raça": "Eu deixo claro no meu livro que o apartheid, como está sendo praticado agora na Cisjordânia, não está baseado em racismo ou divisões étnicas. Está baseado em tomadas de terras palestinas por uma minoria de israelenses" (CARTER, CNN, 27.11.2006). Entretanto, essa afirmação era problemática, como foi bem lembrado várias vezes, inclusive por apoiadores: "Mesmo para aqueles que não rejeitam imediatamente a comparação, ainda há uma falha óbvia [...] que ele continuamente precisa tratar. A palavra apartheid implica racismo como motivação" (THOMPSON, 10.12.2006). Ou, mais ironicamente: "Boa tentativa, Jimmy. Tentar eliminar raça da palavra apartheid é tão forçado quanto tentar eliminar judeu de sionismo. Não funciona" (COHEN, 07.02.2007).

Finalmente, para alguns raros escritores pró-palestinos, a analogia não foi tão longe, e as interpretações que Ihe deram, como sendo a principal acusação contra Israel, vai muito além do que o autor pretendia: "Carter está totalmente certo [...]. Na verdade, ele apenas tocou na ponta do iceberg (QIZILBASH, 20.01.2007), ou: "em muitos aspectos, a opressão de Israel é ainda mais severa" (BARGOUTI, 18.03.2009).

Alguns comentaristas favoráveis expressaram apoio parcial à analogia, alegando que seu uso foi justificado por chamar a atenção a potenciais evoluções da ocupação (argumentum ad futurum judicium). Um deles sugeriu que, embora apartheid seja uma "analogia problemática", "Israel pode muito bem encontrar-se indubitavelmente marcado com o rótulo apartheid (...). Isso pode evitar que ele se torne, ainda que a seus próprios olhos, o que já está se 
EID\&A - Revista Eletrônica de Estudos Integrados em Discurso e Argumentação, Ilhéus, n. esp. ADARR, mai.2016.

tornando: um sistema moralmente inaceitável de dominação?" (POLAKOWSURANSKY, 01.2007). O Ministro da Defesa israelense foi citado usando a analogia dessa forma em 1999 (COHEN, 20.04.2009). Discutirei melhor esse assunto na conclusão.

\section{Pathos: (mal)comunicar com analogias?}

Alguns comentaristas discutiram os efeitos das analogias em relação aos auditórios, sobretudo em razão do prestígio dos autores, unindo, dessa forma, pathos e ethos. Como de costume, esses comentaristas focalizaram o efeito que a analogia poderia ter sobre outros, além de si mesmos - o que é conhecido como "efeito de terceira pessoa" (PERLOFF, 1999), em pesquisa midiática.

Ambos os autores estavam cientes do elemento pathos na utilização da analogia, mas de diferentes formas. Carter mencionou essa questão a um jornalista assistente, observando que o título era "ideia dele" e que tinha sido "questionado" por seu editor (THOMPSON, 10.12.2006). Partidários de Carter alegaram que o desejo de agitar a opinião pública poderia justificar o uso da analogia: "A análise de Carter equivale a uma provocação interessante para uma América em que Iraque, mudanças políticas internas, abatimento e tabus pós-11 de setembro têm esmaecido o debate sobre a Palestina" (COHEN, 07.02.2007). "Uma América": é digno de nota o enorme auditório amorfo assumido aqui pelo comentarista.

Mesmo os críticos da Carter reconheceram, relutantemente, que essa estratégia poderia ser eficaz, especialmente em referências posteriores, na medida em que a analogia ia ganhando espaço. Assim, em 2009, num artigo muito crítico sobre uma conferência contra o racismo, organizada pela UNESCO, em Genebra, leu-se: "Um debate intitulado 'apartheid israelense' homenageia o livro do ex-presidente dos EUA, Jimmy Carter: Palestine: Peace Not Apartheid (dois pontos adicionados). A ideia foi aclamada como uma valiosa ferramenta para a mobilização política e solidária" (Jerusalem Post, 20.04.2009). Carter disse a um jornalista que ele esperava, por meio do seu livro, relançar o processo de paz; levou mais tempo "debatendo sua escolha de palavras" (THOMPSON, 10.12.2006).

Parece que ele subestimou o problema do "auditório complexo" (TINDALE, 2004), especialmente relevante em um mundo mediado pela comunicação de massa. Desejando despertar um amplo auditório de seu sono 
EID\&A - Revista Eletrônica de Estudos Integrados em Discurso e Argumentação, Ilhéus, n. esp. ADARR, mai.2016.

assumido, ele atacou um auditório específico: apoiadores de Israel magoados ou escandalizados pela menção de apartheid. Em vez de debater a analogia, esse auditório atacou-a e a seu autor.

O caso de Saramago é diferente. Ao falar sobre os israelenses e seu exército como "rentistas do Holocausto", Saramago observou: "Foi o fato de eu ter posto o dedo na ferida de Auschwitz que os fez sobressaltar" (28.12.2012). O lugar de seu enunciado original é aqui importante: Saramago falou de Rammallah, na presença de jornalistas israelenses, e assim, ao que parece, queria provocar especificamente um público israelense. Diferente de Carter, ele não parecia desapontado ou constrangido, nas entrevistas, pelo furor que tinha provocado.

Também diferente de Carter, o uso da analogia de Saramago recebeu pouco apoio, e o tipo de apoio que ele encontrou foi sempre qualificado. Por exemplo, um comentarista britânico afirmou: "Isso (a vontade de provocar, observação do autor), presumo, é porque Saramago obteve para Auschwitz o absoluto, certificado, universal - e até agora irremediavelmente banalizado símbolo do mal" (BURUMA, 26.04.2002). O próprio Saramago foi o único comentarista a oferecer uma justificativa completa de sua analogia: "Ele (Saramago) acrescentou que, como escritor, esta foi sua prerrogativa: fazer comparações emotivas, a fim de provocar a consciência das pessoas" (HASS, 26.03.2002).

\section{Argumentos Ethóticos: apelo à autoridade, ad hominem}

Passando do pathos ao ethos, e de auditórios a autores, irei, primeiramente, referir-me ao apelo à autoridade, argumento ad verucundiam, baseado nas características sociais dos autores, e, em seguida, ao argumento ad hominem, baseado nas suas personalidades. Como acontece frequentemente numa polêmica, quando a "função da credibilidade" de uma pessoa é discutida (WATSON, 1999), ambos os argumentos foram, muitas vezes, considerados conjuntamente.

Ambos os autores são personalidades públicas dotadas de competência específica: um é escritor vencedor do prêmio Nobel, o outro, ex-presidente dos Estados Unidos (com um histórico diplomático de agente de acordos do Camp David). Nas manchetes e/ou nas seções Painel do Leitor, os comentaristas sempre se lembravam dessas qualificações, como por exemplo: "Vencedor do Prêmio Nobel: Ramallah se tornando um campo de 
EID\&A - Revista Eletrônica de Estudos Integrados em Discurso e Argumentação, Ilhéus, n. esp. ADARR, mai.2016.

concentração" (HASS, 26.03.2002). Igualmente, Jimmy Carter foi apresentado como (ex)-presidente - sempre com uma lembrança ao seu papel político no Oriente Médio. Tal posição social considerável explica o murmurinho gerado por suas analogias. Até mesmo comentaristas hostis refutaram-nas, observando o "peso social" dos autores. Pela importância das vozes por trás das analogias é que chamo de casos "Auschwitz- Saramago" e "Apartheid Carter".

De modo geral, essa autoridade foi raramente usada em apoio às analogias. Uma notável exceção é esta, novamente de autor pró-palestino: "Políticas repressivas e racistas de Israel em 1967 - o território palestino ocupado foi reconhecido como constituinte do apartheid por vários formadores de opinião, tais como o arcebispo Desmond Tutu, o ex-presidente dos EUA Jimmy Carter, o ex-Observador Especial da ONU dos direitos humanos Prof. John Dugard, entre outros" (BARGOUTI, 18.03.2009). Esse é um bom exemplo do que Watson (1992, p. 199) chama de "efeito pedestal". Seguindo uma abordagem semelhante, Carter foi considerado (no Reino Unido) "a personalidade mais significativa do mundo a ter feito a comparação entre Israel e o apartheid da África do Sul" (FRIEDLAND, 07.06.2008).

Muitas vezes para Carter e sempre para Saramago, o argumento comum era: apesar de suas autoridades como escritor/ex-presidente, eles usaram uma problemática/irrelevante/ultrajante analogia. Os comentaristas contrastaram os títulos de prestígio de ambos os autores com a pobreza de seus argumentos: "O impulso de usar a fama para ajudar os outros é nobre", mas "grandes escritores podem dizer coisas notavelmente tolas" (BURUMA, 26.04.2002). O diretor do Simon Wiesenthal Center chamou a declaração de Saramago de "uma comparação absurda, que mostra claramente que a excelência em literatura não é absolutamente nenhuma garantia de competência em história" (EVANS, 28.12.2002).

Um meio de reforçar a autoridade dos autores foi o uso de uma forma específica do argumento tu quoque (até tu). Esse argumento normalmente significa: "Você me culpa por fumar, mas você também fuma muito". Entretanto, nessa controvérsia, a lógica é mais complexa e conduz à seguinte forma: "Você afirma que essa analogia é prejudicial para os israelenses, mas (pró) israelenses, que deveriam raciocinar como você, usam-na também”. A forma tu quoque é mais usada por jornalistas que cobrem o conflito para justificar a culpa de um lado ou de outro (BOURDON, 2015). 
EID\&A - Revista Eletrônica de Estudos Integrados em Discurso e Argumentação, Ilhéus, n. esp. ADARR, mai.2016.

$\mathrm{O}$ argumento tu quoque foi especialmente popular para Carter e seus apoiadores. Ele observou repetidamente que os israelenses fizeram uso da analogia para criticar a ocupação. Uma crítica favorável (THOMPSON, 10.12.2006) citou o correspondente principal dos EUA no jornal israelense Haaretz, ao afirmar que "não há provas materiais suficientes que provem que o apartheid exista nos territórios ocupados de uma forma ou de outra", o que "reforça uma questão que Carter sempre apresenta: é muito mais comum ouvir falar do comportamento do governo israelense sendo debatido em Israel do que aqui".

Esse último exemplo nos conduz à segunda categoria de argumentos ethóticos, o ad hominem, que se move a partir de competências sociais, como escritor ou ex-presidente, à credibilidade da própria pessoa, ao seu caráter. Isso pode ser empregado de diversas maneiras, (METCALF, 2005): questionando a autoconsistência do autor, tendo mais intimidade e questionando suas integridades pessoais ou morais. $O$ argumento ad hominem foi utilizado apenas na primeira forma por Carter. Somente Saramago "apreciou" os ataques, principalmente do último tipo. Isso pode ser atribuído a duas diferenças entre os autores: considerou-se que Carter possuía alguma competência política no Oriente Médio e tinha uma boa reputação pessoal (um comentarista chamou-lhe de "um ícone" - ver abaixo); Saramago, por outro lado, não foi considerado competente e não tinha tal registro pessoal prévio.

Abraham Foxman, presidente do Anti-Defamation-League, fez o mais severo ataque ad hominem contra Carter: "Ele está provocando, ele é ultrajante, ele é preconceituoso" (primeira citação em BOSMAN, 14.12.2006). Na mais severa crítica ao livro, Dershowitz (02.12.2006) usou o ad hominem pela implicação: "Palestine: Peace Not Apartheid (dois pontos adicionados) é tão tendencioso que levanta a questão sobre o que motivaria um homem decente como Jimmy Carter a escrever um livro tão indecente". Embora Carter tenha sido referido como "decente", essa decência é simultaneamente questionada. Num contexto mais amplo do debate, em que a suspeita de antissionismo (se não antissemitismo) foi levantada sobre os usuários da analogia apartheid, a pergunta sem resposta é grave.

Essa implicação foi desenvolvida por Deborah Lipstadt, pesquisadora sobre a negação do Holocausto. Depois de notar que era "difícil criticar um ícone", ela escreveu que o livro "ignora um legado de maus-tratos, expulsão e 
EID\&A - Revista Eletrônica de Estudos Integrados em Discurso e Argumentação, Ilhéus, n. esp. ADARR, mai.2016.

assassinato cometidos contra os judeus" (LIPSTADT, 20.01.2007). Entrevistada mais tarde, ela enfatizou que a cronologia no livro de Carter "não listou nada de importante entre 1939 e 1947", o que ela interpretou como negação softcore $^{7}$ (Jerusalem Post, 20.01.2007). Isso retrata Carter como um quase- negador do Holocausto.

Um argumento semelhante foi feito por dois críticos que afirmaram explicitamente que Carter estava, na verdade, tentando "deslegitimar" Israel (uma declaração cada vez mais usada contra os críticos de Israel na década de 2000 - CHARBIT, 2013): "A sua invocação à palavra criada oficialmente pela doutrina racista da África do Sul foi uma forma de desacreditar a base moral para a existência de Israel" (FREEDMAN, 26.02.2007).

Alvin Rosenfeld, em nome do grupo mais antigo de defesa judaica nos EUA, American Jewish Committee, atacou Carter, juntamente com outros críticos de Israel - e fez a conexão entre as duas analogias: "Eles estão ajudando a produzir pontos de vista [antissemitas] sobre o respeitável Estado judeu - por exemplo, como um Estado nazista, comparável ao Apartheid da África do Sul" (citado em KARON, 14.09.2007). Esse é um argumento a respeito do pathos e ethos em conjunto, indiciando o autor às possíveis consequências da analogia. A ameaça não é Israel se tornar um Estado de apartheid, como é para os usuários do argumentum ad futurum judicium, mas essa afirmação contribuirá para "deslegitimá-lo": duas formas bem diferentes de chamar a atenção.

Para Saramago, o uso de ad hominem foi muito mais pessoal: "Um homem que compara as agruras de um povo a Auschwitz [...] faz uso frívolo do assassinato de milhões por uma pequena vantagem pessoal" (DALRYMPLE, 12.04.2002). Colegas escritores, especialmente israelenses, embora associados à esquerda e ao que é conhecido em Israel como o "campo da paz", não foram menos ferozes. A.B. Yehoshua afirma: "Não é só a ignorância, é a profundidade da maldade" (AP, 26.03.2002). Amos $\mathrm{Oz}$ combateu Saramago com a comparação: "A ocupação israelense é injusta, mas compará-la aos crimes dos nazistas é como comparar Saramago a Stalin" (Ibidem) - uma referência às crenças comunistas de longa data do escritor, que foram usadas contra ele por outros comentaristas.

7 N.T.: Soft-core é um gênero pornográfico sem exposição explícita de órgãos genitais. 
EID\&A - Revista Eletrônica de Estudos Integrados em Discurso e Argumentação, Ilhéus, n. esp. ADARR, mai.2016.

6. Resumo e conclusão: ultrajante, mas inevitável

Para resumir, ambos os debates pouco disseram sobre a precisão factual; argumenta ad judicium foram raramente usados, e poucos comentaristas (apesar da tentativa do próprio Jimmy Carter) atenderam ao apelo de Perelman para as analogias "serem mantidas dentro de certos limites", a fim de "não prejudicar sua função de fortalecer a convicção" (PERELMAN e OLBRECHTS-TYTECA, 1969, p. 385).

A maioria dos argumentos mencionados pertenceu ao reino dos argumentos emocionais (WATSON, 1992): pathos, ad hominem, ad verucundiam. Todos os comentaristas, seja qual for sua posição, expressaram emoções sobre as analogias ou reagiram às emoções assumidas por outros. Para ambas as analogias, apesar de diferentes foros, as hostis reações foram similares: eles entenderam as analogias como ataques a Israel como um regime racista (mais do que uma expressão de apoio aos palestinos), feitas a fim de provocar o público. Considerou-se que ambos os autores usaram seu prestígio para divulgar as analogias, e alguns perceberam isso como evidência de um plano dissimulado anti-israelense, ou mesmo antissemita. Em suma, o logos foi devorado pelo pathos e ethos. O Quadro 1 resume isso:

\section{QUADRO 1 - Estrutura da argumentação em duas controvérsias sobre Israel-} Palestina

\begin{tabular}{|l|l|l|}
\hline & Auschwitz-Saramago & Carter-Apartheid \\
\hline $\begin{array}{l}\text { Arg. ad judicium } \\
\text { Rejeição total adequação }\end{array}$ & $\begin{array}{l}\text { Rejeição, ou apoio } \\
\text { qualificado } \\
\text { especialmente quanto } \\
\text { ao futuro (apartheid } \\
\text { como ameaça) }\end{array}$ \\
\hline Pathos: Provocação & $\begin{array}{l}\text { Na maioria das vezes, } \\
\text { rejeição total; } \\
\text { ou explicável, mas em } \\
\text { vão }\end{array}$ & $\begin{array}{l}\text { Rejeição ou aceitação } \\
\text { qualificada }\end{array}$ \\
\hline Ethos: ad verucundiam & $\begin{array}{l}\text { Rejeição } \\
\text { (incompetência) }\end{array}$ & $\begin{array}{l}\text { Aceitação, ou rejeição } \\
\text { qualificada }\end{array}$ \\
\hline Ethos: tu quoque & $\begin{array}{l}\text { Quase não usado; } \\
\text { apenas contra "ambos } \\
\text { os lados" }\end{array}$ & $\begin{array}{l}\text { Usado por (apoiadores } \\
\text { de) Carter (a respeito } \\
\text { dos israelenses) }\end{array}$ \\
\hline Ethos: ad hominem & Usado algumas vezes & \begin{tabular}{l} 
Usado muito raramente \\
\hline
\end{tabular}
\end{tabular}


EID\&A - Revista Eletrônica de Estudos Integrados em Discurso e Argumentação, Ilhéus, n. esp. ADARR, mai.2016.

Muitos comentaristas pareceram reagir às analogias como se seu uso fosse algo novo ou raro (enquanto poucos observaram o oposto, que elas já haviam sido utilizadas, e até mesmo "banalizadas"). Um único comentarista (POLLAK, 03.02.2007) mencionou um uso prévio feito por Idi Amin Dada, "o ditador assassino de Uganda", num discurso na Assembleia Geral da ONU, em 1975, mas isso foi mais um argumento ad hominem contra Carter - associandoo a um personagem histórico desonesto - do que uma discussão sobre a história da analogia.

Essa sensação de novidade diz mais sobre o poder das analogias do que sobre sua atual história. Uma breve pesquisa mostra que ambas têm sido comumente utilizadas, e não apenas contra as políticas israelenses. Desde os anos cinquenta, os líderes israelenses usaram comparações e analogias com o nazismo contra os inimigos de Israel (SEGEV, 1993, passim), e também contra outros. Hoje, a direita de Israel continua a usar analogias nazistas contra os inimigos reais ou imaginários do país.

Comparações de Israel com o nazismo têm sido usadas desde 1967, especialmente em círculos radicais de esquerda "dispostos a romper os tabus ligados ao Holocausto ou ao antissemitismo" (POLIAKOV, 1983, p. 153). Elas reapareceram durante a Guerra do Líbano, em 1982, (KOREN, 1996) e também durante a primeira e a segunda intifadas (BOURDON, 2009). No corpus, entretanto, o argumento tu quoque foi raramente usado em relação aos próisraelenses, mas muito frequentemente para criticar ambos os lados, os próisraelenses e os pró-palestinos, por ser inutilmente "compelido a invocar o Holocausto" (CESARINI, 19.04.2002).

Quanto ao apartheid, qualquer sistema de separação rígida direcionado contra uma dada população tem sido chamado de apartheid - especialmente desde a queda do regime Apartheid. Usuários dos argumentos tu quoque deram muitos exemplos dos usos israelenses da analogia aplicada à ocupação. Antes de Carter, dois livros haviam incluído as palavras apartheid e Israel em seus títulos (BISHARA, 2003; DAVIS, 2003), provocando muito menos alvoroço. Em 2005, a Semana Israel-Apartheid foi iniciada por ativistas própalestinos, mas passou quase despercebida.

De fato, a escrita deste artigo coincidiu com uma onda de novos usos e debates sobre as analogias, especialmente em relação ao apartheid. No momento da escrita, foi divulgado que o secretário de Estado John Kerry usou a analogia no argumentum ad futurum judicium. Na ocasião, alguns 
EID\&A - Revista Eletrônica de Estudos Integrados em Discurso e Argumentação, Ilhéus, n. esp. ADARR, mai.2016.

comentaristas desenterraram uma citação de Ben Gurion como o primeiro usuário israelense do argumento (cf. ADLER, 03.05.2014). Mas mesmo a analogia com a política nazista (não o Holocausto - embora possa ser difícil fazer a distinção) tem sido defendida em Israel (uma boa base para o uso futuro do argumento tu quoque).

Amos Oz (que prontamente condenou Saramago, em 2002) comparou jovens radicais colonos aos neonazistas (AFP, 10.05.2014). Insistindo em que não se deve confundir uma analogia com o próprio Holocausto, o renomado historiador do Holocausto, Saul Friedlander (18.05.2014), fez um apelo surpreendente para o uso da analogia entre a política nazista e política de Israel nos territórios ocupados. Ele reconheceu que essa era uma pista escorregadia (uma reivindicação que minha análise apoia amplamente), mas justificou seu apelo, apontando uma rivalidade política: o Holocausto foi "sequestrado pela direita" e usado para se referir aos inimigos reais ou imaginários de Israel, por isso poderia ser utilizado pela esquerda também. Essa observação contradiz a atitude dos historiadores face às analogias que tendem a alertar contra "comparar o incomparável" (DETIENNE, 2008, p. X).

Esses apelos às analogias levantam outro problema que merece uma análise própria: elas são produzidas dentro de Israel, objetivando outros israelenses. Mas a analogia ressoa de modo diferente - sobretudo a Nazista/Holocausto - tanto quanto a crítica de Israel, quando é "exportada" (BOURDON, 2009).

Assim, ambas as analogias têm sido muito usadas e muito condenadas. Por que esse processo repetitivo? Os regimes Nazista e Apartheid são conhecidos como símbolos do mal. Ambas as analogias referem-se à discriminação sistemática racial, que tem sido amplamente condenada no século XX, especialmente na sombra do Holocausto (CHAUMONT, 1997). Embora elas possam ser vistas como (sub)analogias de compaixão, que objetivam evocar piedade às vítimas, elas são, na sua maioria, compreendidas como analogias de acusação que visam a responsabilizar seus perpetradores, provocando, dessa forma, indignação, e até mesmo ódio. As vítimas das analogias (os palestinos como judeus ou negros) estavam notavelmente ausentes dos debates.

Além disso, ao contrário das analogias mais nacionais que mencionei na seção de abertura, as analogias aqui em questão são rapidamente 
EID\&A - Revista Eletrônica de Estudos Integrados em Discurso e Argumentação, Ilhéus, n. esp. ADARR, mai.2016.

compreendidas pelos auditórios globais e são, portanto, percebidas como analogias cosmopolitas, o que reforça seu poder assumido.

Em um artigo sobre o uso de monstros e dragões em cartoons políticos desde o início do gênero, Gombrich (1963, p. 139) observou: "Quando perplexos e frustrados, todos nós fazemos recair o nosso olhar para 0 primitivo". Em um contexto de mídia global, competitiva, saturada com eventos, pode-se dizer que certas analogias, especialmente aquelas que invocam nazistas ou o Holocausto, e, em menor escala, apartheid, são o nosso "histórico primitivo".

\section{Referências}

BISHARA, M. Palestine/Israel: Peace or Apartheid. London: Zed Books (French edition 2001), 2003.

BOURDON, J. Strange Strangers. The Jerusalem correspondents in the network of nations, Journalism, vol. 1, n. 16, 2015. Boecke, 2009.

. Le Récit Impossible. Le conflit israélo-palestinien et les medias. Paris: De

CHARBIT, D. The Uses of De-legitimation of Israel in the Pro-Israeli Discourse. Tel Aviv University, Kantor Forum, 2013.

CHAUMONT, J.M. La concurrence des victimes. Paris: LaDécouverte, 1997.

DAVIS, U. Apartheid Israel: possibilities for the struggle within. London: Zed Books, 2003.

DETIENNE, M. Comparing the Uncomparable. Stanford: Stanford University Press, 2008.

FLEURY, B. and WALTER, J.(eds). Les médias et le conflit israélo-palestinien. Metz: Université de Metz, 2008.

GLASER, D. Zionism and apartheid: A moral comparison. Ethnic and Racial Studies, vol. 26, n. 3, p. 403-421, 2003.

GOMBRICH, E.H. The Cartoonist's Armoury. In. Meditations on a Hobby Horse. London: Phaidon Press, p.127-142, 1963.

HOUCHIN-WINFIELD, B. et al. History as the Metaphor through which the Current World is Viewed. Journalism Studies, vol. 3, n. 2, p. 289-300, 2002. 
EID\&A - Revista Eletrônica de Estudos Integrados em Discurso e Argumentação, Ilhéus, n. esp. ADARR, mai.2016.

KENNEDY, V. Intended Tropes and Unintended Metatropes in Reporting on the War in Kosovo. Metaphor and Symbol, vol. 15, n. 4, p. 253-265, 2000.

KITIS, E. and MILAPIDES, M. Read it and believe it. How metaphors construct ideology in news discourse. A Case Study. Journal of Pragmatics, 28, p. 557-590, 1997.

KOREN, R. Les enjeux éthiques de l'écriture de presse. Paris: l'Harmattan, 1996.

KOREN, R. Beyond neutrality and/or political commitment. Bulletin du Centre de recherche français de Jérusalem, 23, 2012. Disponível em: http://bcrfj.revues.org/6779. Acesso em: 05.04.2014.

KOREN, R. Ni normatif ni militant: le cas de l'engagement éthique du chercheur. Argumentation et Analyse du Discours 11, 2013. Disponível em: http://aad.revues.org/1572. Acesso em: 23.11.2014.

LAKOFF, G. Metaphor and War, Again. 2003. Disponível em: http://www.alternet.org/story/15414/metaphor_and_war,_again. Acesso em: 06.06.2014.

LULE, J. War and its metaphors: news language and the prelude to war in Iraq, 2003. Journalism Studies, vol. 5, n. 2, p. 179-190, 2004.

METCALF, R. Rethinking the Ad hominem: A Case Study of Chomsky. Argumentation, 19, p. 29-52, 2005.

NEUSTADT, R. and MAY, E.R. Thinking in Time: The Uses of History for Decision Makers. New York: The Free Press, 1986.

PERELMAN, C; OLBRECHTS-TYTECA, L. The New Rhetoric. A Treatise on Argumentation. Notre-Dame: UND Press, 1969 [1958].

PERLOFF, R.M. The third-person effect: A critical review and synthesis. Media Psychology 1: 353-37, 1999.

POLIAKOV, L. De Moscou à Beyrouth. Paris: Calmann-Lévy, 1983.

RICOEUR, P. La métaphore vive. Paris: Seuil, 1975.

SEGEV, T. The Seventh Million. The Israelis and the Holocaust. New York: Hill and Wang, 1993.

SONTAG, S. Aids and its Metaphors. New York: Anchor, 1990.

TAGUIEFF, P.A. Rising from the Muck: The New Anti-Semitism in Europe. Chicago: Ivan R. Dee, 2004. 
EID\&A - Revista Eletrônica de Estudos Integrados em Discurso e Argumentação, Ilhéus, n. esp. ADARR, mai.2016.

TAGUIEFF, P.A. Le retour de la question juive, ou la nouvelle propagande antisioniste, 2009. Disponível em:

http://www.terredisrael.com/DossierPDF/Taguieff_Le\%2oretour\%20de\%2ola\%20questi on\%20juive_Perspectives_septembre\%202009-1.pdf. Acesso em: 26.05.2014.

TINDALE, C.W. Rhetorical Argumentation. Thousand Oaks, Ca.: Sage, 2004.

VAN DIJK, T. News as Discourse. Hillsdale, NJ: Erlbaum, 1988.

WATSON, D. The Place of Emotion in Argument. University Park, Pennsylvania: Pennsylvania State University Press, 1992.

WATSON, D. Ethotic Arguments and Fallacies. The Credibility Function in Multi-Agent Dialogue Systems. Pragmatics \& Cognition, vol. 7, n. 1, p. 177-203, 1999.

ZELIZER, B. et al. How bias shapes the news: Challenging the New York Times' status as a newspaper of record on the Middle East. Journalism, vol. 3, n. 3, p. 283-307, 2002.

CORPORA (retirados diretamente do Lexis-Nexis, na categoria "English News")

ADLER, J. David Ben-Gurion, like Kerry, warned of future Apartheid. Times of Israel (3.05.2014). Disponível em: http://blogs.timesofisrael.com/david-ben-gurion-like-kerrywarned-of-future-apartheid/. Acesso em: 18. 05.2014.

AFP/Ynet News (10.05.2004). Amos Oz: 'Price tag' vandals are ‘Hebrew neo-Nazis'.

AFP - Agence France-Press (25.03.2002). Nobel Laureate Saramago compares Israeli occupation to Auschwitz.

AP (26.03.2002). Author Saramago sets off storm by comparing blockaded Palestinian town to Nazi death camp.

BISHARAT, G. Truth At Last, While Breaking a U.S. Taboo of Criticizing Israel. Philadelphia Inquirer (02.02.2007).

BARGOUTI, O. Review of Palestine Peace not Apartheid. Palestinian Chronicle. (18.03.2009).

BBC website (30.03.2002). Interview with Saramago.

BLACK, I. Divided Loyalties. The Guardian (17.02.2007).

BOSMAN. J. Carter's view of Israeli 'Apartheid' stirs furore. New York Times (14.12.2006).

BURUMA, I. Jose Saramago's comparison of the West Bank to Auschwitz proves one thing: writers should stay out of politics. The Guardian (26.04.2002). 
EID\&A - Revista Eletrônica de Estudos Integrados em Discurso e Argumentação, Ilhéus, n. esp. ADARR, mai.2016.

CESARINI, D. A last lesson from the Holocaust. The Times Higher Education Supplement (19.04.2002).

COHEN, R. Jimmy Carter attempts to provoke, and succeeds. International Herald Tribune (07.02.2007).

COHEN, R. Israel, Iran and Fear. International Herald Tribune (20.04.2009).

CNN (27.11.2006). Interview with Jimmy Carter by Larry King.

COOK, J. A comparative review of Flat Earth news and newspeak. Atlantic Free Press (27.11.2009).

DALRYMPLE, T. Trivializing the Holocaust. Auschwitz is not a metaphor. City Journal (12.04.2002).

DERSHOWITZ, A. For Carter, a book-length smear on Israel. Canada. National Post (02.12.2006).

EVANS, J. Profile: The Militant Magician. The Guardian (28.12.2002).

FREEDMAN, S.G. Carter and the Christians The Jerusalem Post (26.02.2007).

FRIEDLAND, J. We have moral authority. The Guardian (07.06.2008).

FRIEDLANDER, S. Zionism has been captured by Far-Right. Ha'aretz (18.05.2014).

HAKIN, H. Off-key comparison. The New York Sun (30.11.2004)

HASS, A. Nobel winner: Ramallah being turned into concentration camp. Ha'aretz (26.03.2002).

KARON, T. Growing Dissent among American Jews. Atlantic Free Press (14.09.2007).

Jerusalem Post (20.01.2007). Interview with Deborah Lipstadt.

Jerusalem Post (20.04.2009). NGOs bash Israel ahead of Durban II conference.

Jewish Forward (19.01.2007). If it's 'Apartheid', then who's the Palestinian Mandela?

LIPSTADT, D. Jimmy Carter's Jewish Problem. Washington Post (20.01.2007).

NPR (12.01.2007). Roundtable.

NPR (25.01.2007). Interview with former President Jimmy Carter.

POLAKOW-SURANSKY, S. Indictment or Challenge? Palestine Peace not Apartheid, by Jimmy Carter. American Prospect (01.2007). 
EID\&A - Revista Eletrônica de Estudos Integrados em Discurso e Argumentação, Ilhéus, n. esp. ADARR, mai.2016.

POLLAK, J. South Africa: the Trouble with the Apartheid Analogy. Africa News (03.02.2007).

QIZILBASH, BH. Review of Palestine peace not apartheid. The Nation (20.01.2007).

THOMPSON, B. Peace Provocateur; Jimmy Carter's New Hammer? It Looks an Awful Lot Like a Book. The Washington Post (10.12.2006).

Como citar :

BOURDON, Jérôme. Ultrajantes, inevitáveis? Debatendo analogias históricas na cobertura do conflito israelo-palestino. Trad. Kelly Cristina de Oliveira e Moisés Olímpio Ferreira. EID\&A - Revista Eletrônica de Estudos Integrados em Discurso e Argumentação, Ilhéus, n. esp. ADARR, p. 23-46, mai.2016. 